\title{
Human Alveolar Macrophages Have 15-Lipoxygenase and Generate 15(S)-Hydroxy-5,8,11-cis-13-trans-eicosatetraenoic Acid and Lipoxins
}

\author{
Bruce D. Levy, * Mario Romano, * Harold A. Chapman, ${ }^{\ddagger}$ John J. Reilly, ${ }^{\star}$ Jeffrey Drazen, ${ }^{*}$ and Charles N. Serhan * \\ ${ }^{*}$ Hematology-Oncology and ${ }^{\ddagger}$ Pulmonary Divisions, Department of Medicine, Brigham and Women's Hospital \\ and Harvard Medical School, Boston, Massachusetts 02115
}

\begin{abstract}
Eicosanoids derived from lipoxygenase (LO)-catalyzed reactions play important roles in pulmonary inflammation. Here, we examined formation of LO-derived products by human alveolar macrophages (HAM). HAM converted $\left[1-{ }^{14} \mathrm{C}\right]-$ arachidonic acid to a product carrying ${ }^{14} \mathrm{C}$-radiolabel that was identified as 15(S)-hydroxy-5,8,11-cis-13-trans-eicosatetraenoic acid (15-HETE) by physical methods. 15-LO mRNA was demonstrated in HAM by reverse transcription-polymerase chain reaction. Incubation of HAM for $3 \mathrm{~d}$ with interleukin 4 (IL-4) before exposure to $\left[1-{ }^{14} \mathrm{C}\right]$ arachidonic acid led to both increased mRNA for 15-LO and a 4-fold increase in 15-HETE formation. In contrast, 5(S)-hydroxy-6-trans-8,11,14-cis-eicosatetraenoic acid generation was not significantly altered by prior exposure to IL-4. Additionally, lipoxins ( $\mathrm{LXA}_{4}$ and $\mathbf{L X B}_{4}$ ) were detected from endogenous substrate, albeit in lower levels than leukotriene $\mathbf{B}_{4}\left(\mathbf{L T B}_{4}\right)$, in electrochemical detection/high performance liquid chromatography profiles from HAM incubated in the presence and absence of the chemotactic peptide (FMLP) or the calcium ionophore $\left(A_{23187}\right)$. Exposure of HAM to leukotriene $\mathrm{A}_{4}\left(\mathrm{LTA}_{4}\right)$ resulted in a 2fold increase in $\mathrm{LXA}_{4}$ and 10-fold increase in $\mathbf{L X B}_{4}$. These results demonstrate the presence of 15-LO mRNA and enzyme activity in HAM and the production of $\mathrm{LXA}_{4}$ and $\mathrm{LXB}_{4}$ by these cells. Along with 5-LO-derived products, the biosynthesis of 15-LO-derived eicosanoids by HAM may also be relevant in modulating inflammatory responses in the lung. $(J$. Clin. Invest. 1993. 92:1572-1579.) Key words: cytokines • eicosanoids • inflammation • interleukin 4
\end{abstract}

\section{Introduction}

Human alveolar macrophages (HAM) ${ }^{1}$ are cells that may play a major role in host defense, and conversely display significant phlogistic potential (1); there is reason to believe that some of

This work was presented in part at the 11 th Washington International Spring Symposium in Health Sciences on Prostaglandins, Leukotrienes, Lipoxins and Platelet-Activating Factor on 16 May 1991.

Address reprint requests to Dr. Charles Serhan, Hematology-Oncology Division, Brigham and Women's Hospital, 221 Longwood Avenue, Boston, MA 02115. 1993

Received for publication 26 August 1992 and in revised form 7 May

J. Clin. Invest.

(c) The American Society for Clinical Investigation, Inc.

0021-9738/93/09/1572/08 \$2.00

Volume 92, September 1993, 1572-1579 their diverse bioactions may be mediated by the generation of eicosanoids (1). For example, HAM exposed to a variety of stimuli in vitro can generate 5-lipoxygenase (5-LO) products including leukotriene $\mathrm{B}_{4}\left(\mathrm{LTB}_{4}\right)(2,3)$, a potent chemoattractant (reviewed in reference 4). Despite an abundance of 15(S)-hydroxy-5,8,11-cis-13-trans-eicosatetraenoic acid (15-HETE) in bronchoalveolar lavage (BAL) fluid and human lung $(5,6), 15$-lipoxygenase (15-LO) activity has not been documented in HAM. 15-HETE generation in the respiratory tract may be important since, in vitro, this eicosanoid can both regulate LT production (4) and serve as one of the substrates for conversion to lipoxins (reviewed in references 4 and 7).

Cytokines can regulate the formation of LO-derived products. IL-4 is found in the microenvironment of HAM, especially in disease states such as asthma (8). Moreover, macrophages possess IL-4 receptors (9) and the induction of 15-LO by IL-4 was recently demonstrated in human peripheral blood monocytes (10).

Lipoxins (LX), formed by interactions between individual lipoxygenases (reviewed in references 4 and 7 ), are also found in BAL fluid from patients with a variety of respiratory diseases (11). There is growing evidence that these compounds, in submicromolar amounts, act as endogenous regulators of leukotriene (LT)-induced responses (reviewed in reference 7). Despite potential roles for LX in the human lung (12), LX production by HAM has not yet been evaluated.

Given the documented actions for both 15-HETE and LX in the respiratory tract $(4,13,14)$, we have examined HAM contribution to their production. Here, we report that 15 HETE is generated by HAM and that its production is enhanced by IL-4. In addition, evidence is provided for LX generation by HAM from both endogenous and exogenous substrates.

\section{Methods}

Materials. Ionophore $\left(\mathrm{A}_{23187}\right), \mathrm{FMLP}$, aspirin, and indomethacin were from Sigma Chemical Co. (St. Louis, MO). Synthetic eicosanoids were

1. Abbreviations used in this paper: AA, arachidonic acid; BAL, bronchoalveolar lavage; ED, electrochemical detection; HAM, human alveolar macrophages; 5-HETE, 5(S)-hydroxy-6-trans-8,11,14-cis-eicosatetraenoic acid; 15-HETE, 15(S)-hydroxy-5,8,11-cis-13-trans-eicosatetraenoic acid; 13-HODE, 13-hydroxy-9-cis-11-trans-octadecadienoic acid; LO, lipoxygenase; $\mathrm{LTA}_{4}$ (leukotriene $\mathrm{A}_{4}$ ), 5(S)-trans5,6-oxido-7,9-trans-11,14-cis-eicosatetraenoic acid; $\mathrm{LTB}_{4}$ (leukotriene $\left.\mathrm{B}_{4}\right), 5(\mathrm{~S}), 12(\mathrm{R})$-dihydroxy-6,14-cis-8,10-trans-dihydroxyeicosatetraenoic acid; $L X$, lipoxin; $\mathrm{LXA}_{4}$ (lipoxin $\mathrm{A}_{4}$ ), 5(S),6(R), 15(S)-trihydroxy-7,9,13-trans-11-cis-eicosatetraenoic acid; $\mathrm{LXB}_{4}$ (lipoxin $\mathrm{B}_{4}$ ), 5(S), 14(R), 15(S)-trihydroxy-6,10,12-trans-8-cis-eicosatetraenoic acid; $R T$, reverse transcription. 
purchased from Cascade Biochem Ltd. (Reading, England) and radiolabeled arachidonic acid was from NEN Research Products (Boston, MA). Recombinant IL-4 was from Genzyme (Cambridge, MA). Reverse transcription (RT) and PCR buffers, deoxynucleoside triphosphates (dNTPs), and acetylated BSA were obtained from Promega Corp. (Madison, WI), RNacin, Moloney murine leukemia virus (mmLV), and Thermus aquaticus DNA polymerase were from Gibco BRL (Gaithersburg, MD) and Apa-1 and Pst-1 were from Pharmacia Inc. (Piscataway, NJ). Other chromatographic materials and solvents were as described in references 15 and 16.

Cell isolation. HAM were obtained from healthy, nonsmoking subjects who denied taking medication (including aspirin) for at least $7 \mathrm{~d}$ before lavage. None of the donors had a history of asthma, bronchitis, pneumonia, recent viral infection, or other lung disease. All subjects were volunteers and had given written informed consent to a protocol approved by the Brigham and Women's Hospital Committee for the Protection of Human Subjects from Research Risks.

HAM were obtained by BAL using 4-6 50-ml aliquots of sterile $0.9 \%$ saline. All tubing on the bronchoscope was changed just before lavage. The fluid was collected by gentle suction, pooled, and placed in polypropylene tubes in an ice bath until centrifugation $(300 \mathrm{~g}$ for 10 min at $4^{\circ} \mathrm{C}$ ). Cell pellets were suspended in Dulbecco's PBS, pH 7.45. Cell enumeration, viability, and differential cell counts were assessed. Cytocentrifuge preparations of lavaged cells stained with modified Wright-Giemsa were examined microscopically and verified by nonspecific esterase. For incubations with IL-4, HAM $\left(1-1.2 \times 10^{6}\right.$ cells $\left./ \mathrm{ml}\right)$ suspended in conditioned media (RPMI $1640+10 \%$ FCS containing L-glutamine and antibiotics) were seeded into $35-\mathrm{mm}$ multiwell plates. After $1 \mathrm{~h}$ at $37^{\circ} \mathrm{C}$ in atmosphere containing $5 \% \mathrm{CO}_{2}$, nonadherent cells were removed and HAM were supplemented with fresh medium alone or with IL-4 ( $500 \mathrm{pM})$. The incubations were continued at $37^{\circ} \mathrm{C}$ in an atmosphere of $5 \% \mathrm{CO}_{2}$ in air for $72 \mathrm{~h}$.
Incubation conditions. HAM were washed with $\mathrm{PBS}$, then suspended with PBS containing $1 \mathrm{mM} \mathrm{CaCl}_{2}, 1 \mathrm{mM} \mathrm{MgCl}_{2}$, and $1.8 \mathrm{mM}$ ATP, and incubated either intact or after freeze-thaw. HAM were permeabilized to increase substrate availability and LO-derived product formation by rapid freezing in a dry ice-acetone bath, thawed to room temperature (full cycle $\sim 30 \mathrm{~min}$ ), and taken directly for incubations (15). Suspensions were then exposed to arachidonic acid (AA; $20 \mu \mathrm{M}$ ) plus $\left[1-{ }^{14} \mathrm{C}\right] \mathrm{AA}(1.6 \mu \mathrm{M}, 52 \mathrm{mCi} / \mathrm{mmol})$ for $20 \mathrm{~min}$ at $37^{\circ} \mathrm{C}$. Intact cells were also exposed to $A_{23187}(5 \mu \mathrm{M})$. For some incubations, cells were treated with indomethacin $\left(100 \mu \mathrm{M}, 10 \mathrm{~min}, 37^{\circ} \mathrm{C}\right)$ before addition of $\left[1-{ }^{14} \mathrm{C}\right] \mathrm{AA}$. When examined directly after BAL, HAM were washed with PBS and then incubated either alone or in the presence of $A_{23187}(5 \mu \mathrm{M})$, FMLP $(0.1 \mu \mathrm{M})$, or $\mathrm{LTA}_{4}(15 \mu \mathrm{M})$ for $25 \mathrm{~min}$ at $37^{\circ} \mathrm{C}$. All incubations were terminated with iced $\mathrm{MeOH}$ ( $2 \mathrm{vol}$ ) containing either $\mathrm{PGB}_{2}$ or 13-hydroxy-9-cis-11-trans-octadecadienoic acid (13HODE) as internal standards.

Isolation and $R T$ of $R N A$. HAM $\left(2 \times 10^{6}\right)$ were lysed with guanidine isothiocyanate $(4 \mathrm{M})$ to extract total cellular RNA which was isolated by centrifugation through cesium chloride ( $5.7 \mathrm{M}$ ) at 100,000 $g$ for $18 \mathrm{~h}(17)$. Because small amounts of RNA were present, transfer RNA $(20 \mu \mathrm{g})$ from Escherichia coli was added to each sample to serve as carrier before centrifugation. RNA pellets were resuspended in 300 $\mu$ l RNase-free water, phenol/chloroform extracted, ethanol precipitated in the presence of $\mathrm{NaAcetate}$ ( $3 \mathrm{M}, \mathrm{pH} 5.2$ ), dried, resuspended in $50 \mu \mathrm{l}$ of RNase-free water, and quantified by the presence of ultraviolet (UV)-adsorbing material at $260 \mathrm{~nm}$. This procedure was also used with RNA isolated from peripheral blood monocytes (10). Nonsmoker lung RNA was donated by the Brigham and Women's Hospital Lung Transplantation Tissue Bank.

RNA from each volunteer was reverse transcribed as described (18). Briefly, each sample contained $500 \mathrm{ng}$ of total cellular RNA, RT buffer, $1 \mathrm{mM}$ dNTPs, $0.2 \mu \mathrm{g}$ poly ( $\mathrm{T}$ ) antisense coding oligonucleotide

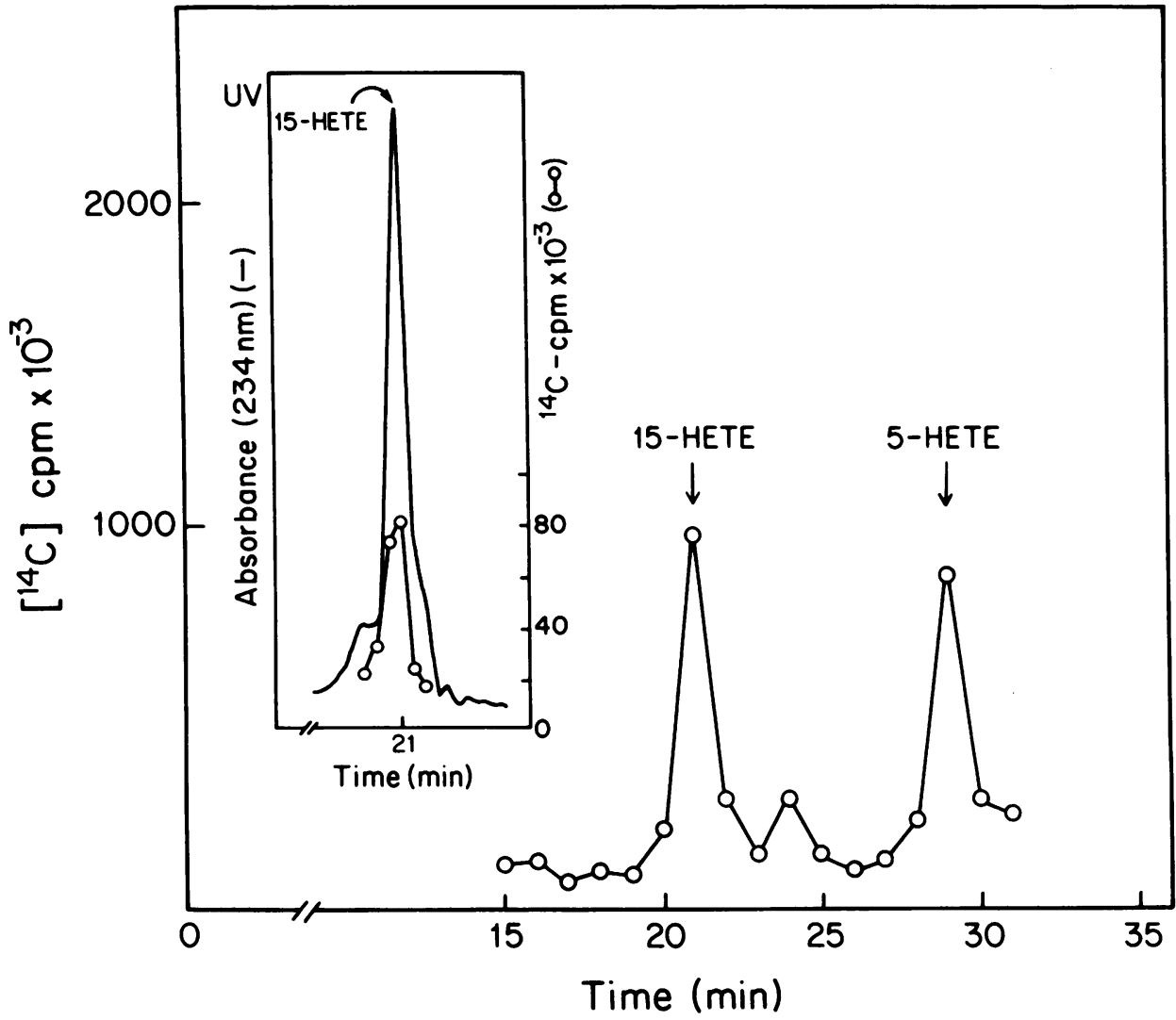

Figure 1. HAM generation of 15 HETE and 5-HETE. HAM were seeded at $10^{6}$ cells $/ \mathrm{ml}$ in $35-\mathrm{mm}$ multiwell plates, exposed to IL-4 $(500 \mathrm{pM})$ or vehicle control for 72 $\mathrm{h}\left(37^{\circ} \mathrm{C}, 5 \% \mathrm{CO}_{2}\right)$, and incubated after a rapid freeze-thaw with $\mathrm{AA}$ $(20 \mu \mathrm{M}):\left[1-{ }^{14} \mathrm{C}\right] \mathrm{AA}(1.6 \mu \mathrm{M}, 52$ $\mathrm{mCi} / \mathrm{mmol}$ ) for $20 \mathrm{~min}$ at $37^{\circ} \mathrm{C}$ Products were extracted, injected on RP-HPLC, and eluted with $\mathrm{MeOH} / \mathrm{H}_{2} \mathrm{O} /$ acetic acid (75:25:0.01, vol/vol/vol) (See Methods). Products eluting with the same retention time as authentic 15-HETE were obtained from several incubations $(n=3)$ with cells from different donors, collected after RP-HPLC, pooled, concentrated, rechromatographed (inset), and eluted as indicated above. Inset: Coelution of 15-HETE from HAM with authentic 15-HETE. 
primer, $40 \mathrm{U}$ RNacin, $60 \mu \mathrm{g}$ acetylated BSA, and $400 \mathrm{U} \mathrm{mmLV}$. After incubation at $25^{\circ} \mathrm{C}$ for $10 \mathrm{~min}$ and $42^{\circ} \mathrm{C}$ for $60 \mathrm{~min}$, the reactions were terminated by heating to $100^{\circ} \mathrm{C}$ for $10 \mathrm{~min}$. Samples were kept at $4^{\circ} \mathrm{C}$ until used.

Preparation of oligonucleotide primers. Oligonucleotide primers were constructed from published cDNA sequences of 15-LO (19) and $\beta$-actin (20). The primers for 15-LO were selected to minimize the considerable sequence homology between 5-, 12-, and 15-LO (21). The primers were synthesized using a model 392 DNA/RNA synthesizer (Applied Biosystems, Inc., Foster City, CA), quantified by UV absorbance at $260 \mathrm{~nm}$, and stored at $4^{\circ} \mathrm{C}$. The sequence of the $15-\mathrm{LO}$ primers was 5' ATGGGTCTCTACCGCATCCGCGTGTCCACT 3' (coding sense) corresponding to bases 1-30 of the cloned full-length sequence and 5' CACCCAGCGGTAACAAGGGAACCTGACCTC 3 (anticoding sense), which anneals to bases 274-303. The $\beta$-actin primers spanned nucleotide positions $1139-1632$ of $\beta$-actin mRNA (20). The predicted sizes of the amplified 15-LO and $\beta$-actin DNA products were 300 and $493 \mathrm{bp}$, respectively.

Amplification of 15-LO cDNAs and identification of products. Each sample contained the sense and anti-sense primers $(0.3 \mu \mathrm{g})$, dNTPs ( $500 \mu \mathrm{M})$, DMSO (5\%), PCR buffer, Thermus aquaticus DNA polymerase ( $2.5 \mathrm{U}$ ), and $5 \mu$ l of each RT mixture (HAM RNA plus $E$. coli T-RNA) to act as a template. The suspensions were overlaid with two drops of mineral oil and amplified for 25-40 cycles in a thermal cycler (M.J. Research, Cambridge, MA). The amplification sequence consisted of denaturation at $96^{\circ} \mathrm{C}$ for $1 \mathrm{~min}$, primer annealing at $55^{\circ} \mathrm{C}$ for $2 \mathrm{~min}$, and extension at $72^{\circ} \mathrm{C}$ for $2.5 \mathrm{~min}$. The reaction was terminated by cooling at $4^{\circ} \mathrm{C}$. After completion of the PCR, $25 \mu \mathrm{l}$ of the suspension was electrophoresed through a $2 \%(\mathrm{wt} / \mathrm{vol})$ agarose gel in TBE buffer (Tris base [ $89 \mathrm{mM}$ ], boric acid [ $89 \mathrm{mM}$ ], EDTA [pH 8.0,2 mM]) containing ethidium bromide $(0.5 \mu \mathrm{g} / \mathrm{ml})$ and photographed with $\mathrm{UV}$ illumination.

Restriction endonucleases, Apa-1 and Pst-1, were identified using the Mac Vector program (version 4.0) with unique targets in the first $300 \mathrm{bp}$ of putative $15-\mathrm{LO}$ and 5-LO products, respectively. The amplified products $(25 \mu \mathrm{l})$ obtained using oligonucleotides for presumed 15 - $\mathrm{LO}$ were incubated $\left(42^{\circ} \mathrm{C}, 16 \mathrm{~h}\right)$ with each enzyme, electrophoresed
Table I. IL-4-induced Increase in 15-HETE Generation

\begin{tabular}{lccc}
\hline & 5-HETE & 15-HETE & 5-HETE/15-HETE \\
\hline \multicolumn{4}{c}{$n g / 10^{6}$ cells } \\
HAM & $6.71 \pm 0.66$ & $4.15 \pm 0.43$ & $1.63 \pm 0.15$ \\
HAM + IL-4 & $11.44 \pm 5.88$ & $20.43 \pm 3.90^{*}$ & $0.52 \pm 0.18^{*}$ \\
\hline
\end{tabular}

HAM $\left(0.95-1.2 \times 10^{6}\right.$ cells $\left./ \mathrm{ml}\right)$ were isolated from BAL fluid and incubated $72 \mathrm{~h}$ in the presence or absence of IL-4 (500 pM). After rapid freeze-thaw, cells were exposed to arachidonic acid $(20 \mu \mathrm{M})$ : $\left[1-^{14} \mathrm{C}\right] \mathrm{AA}(1.6 \mu \mathrm{M}, 52 \mathrm{mCi} / \mathrm{mmol})$ for $20 \mathrm{~min}$ at $37^{\circ} \mathrm{C}$. Products were extracted and chromatographed as described in Methods. Results represent mean \pm SEM from three separate donors. Recovery of internal standard was $74.5 \pm 5.0 \%$. *Statistical significance, $P<0.05$.

through a 3\% (wt/vol) agarose gel in TBE buffer containing ethidium bromide $(0.5 \mu \mathrm{g} / \mathrm{ml})$, and visualized by UV illumination.

Eicosanoid analysis. LO products were extracted and quantitated as in $(15,16)$. After centrifugation, samples were rapidly loaded into cartridges $\left(\mathrm{C}_{18}\right.$ Sep-Paks $)$, washed with $\mathrm{H}_{2} \mathrm{O}$, and eluted with hexane, methyl formate, and $\mathrm{MeOH}$. Materials eluted from methyl formate and $\mathrm{MeOH}$ fractions were concentrated with $\mathrm{N}_{2}$, examined for $\mathrm{UV}$-absorbing materials, and injected into a RP-HPLC system. 6-trans-LTB , $_{4}$, 12-epi-6-trans-LTB $\mathrm{LT}_{4}, \mathrm{LTB}_{4}$, and $\mathrm{LX}$ were resolved using tandem electrochemical (ED)-UV detection with RP-HPLC. This system was equipped with both a Lambda Max UV detector (model 481; Waters Associates, Milford, MA) and an on-line ED, model M 460 (Waters Associates) operated with a $\mathrm{Ag} / \mathrm{AgCl}_{2}$ reference electrode (Waters Associates). The column, a Beckman Instruments Inc. (Palo Alto, $\mathrm{CA}$ ) Ultrasphere-ODS $(4.5 \mathrm{~mm} \times 25 \mathrm{~cm})$ was eluted with $\mathrm{MeOH} / \mathrm{H}_{2} \mathrm{O}$ $(65: 35, \mathrm{vol} / \mathrm{vol})$, trifluoroacetic acid $(1 \mathrm{mM})$, at a flow rate of $1 \mathrm{ml} /$ $\mathrm{min}$. The electrode potential was set at $1.345 \mathrm{~V}$ to optimize the detection of LX and the UV detector was set at $270 \mathrm{~nm}$ (to monitor LT) and

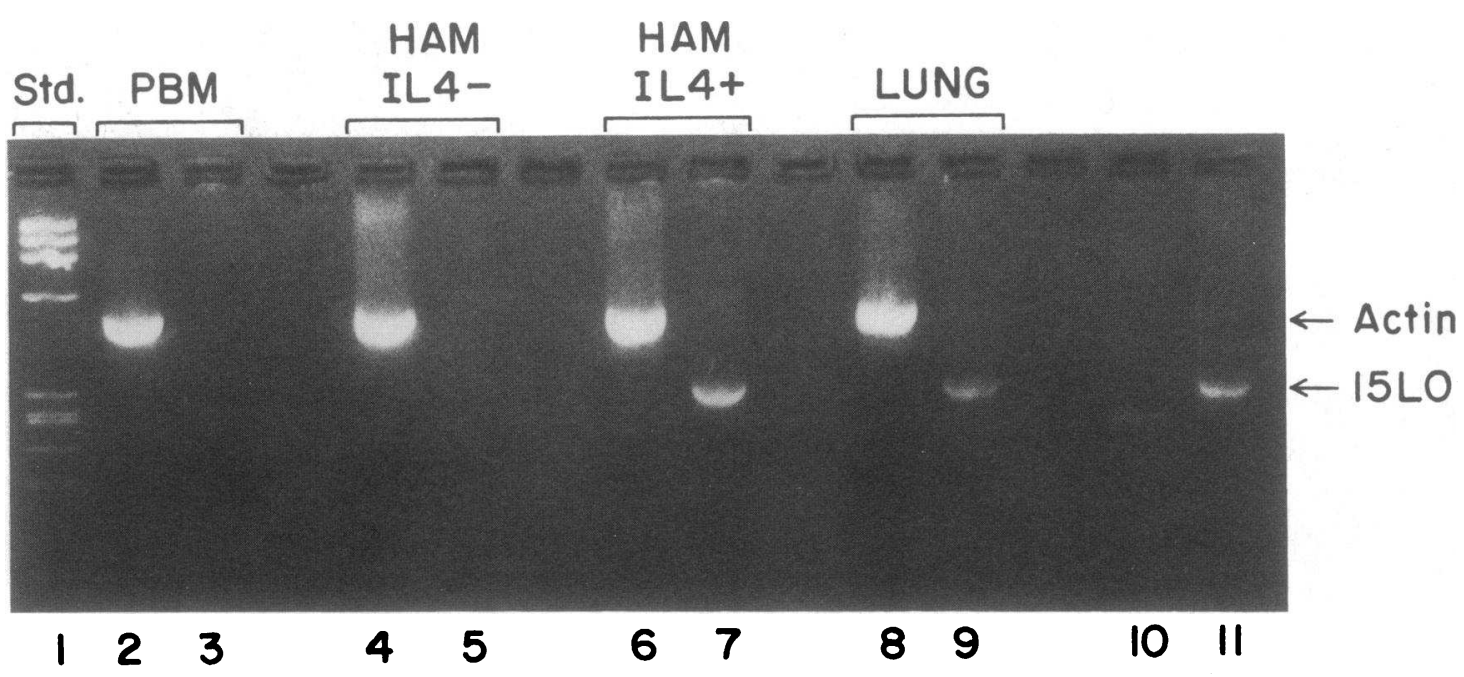

Figure 2. RT-PCR of total cellular RNA from HAM: effect of IL-4. Total cellular RNA was extracted and purified from human peripheral blood monocytes, lung tissue, and alveolar macrophages after $72 \mathrm{~h}$ in the presence or absence of IL-4 (500 pM) (see Methods). RT was performed with RNA ( $500 \mathrm{ng}$ ) using a poly ( $\mathrm{T}$ ) antisense coding primer, and the PCR was carried out in the presence of specific nested primers for either $\beta$-actin ( 25 cycles) (lanes $2,4,6$, and 8 ) or 15 - $\mathrm{LO}$ ( 30 cycles) (lanes $3,5,7$, and 9 ). Equal amounts of the amplified products generated from RNA of HAM in the presence of IL-4 were incubated $\left(18 \mathrm{~h}, 42^{\circ} \mathrm{C}\right)$ with either Apa-1 $(25 \mathrm{U})$ or Pst-1 (10 U) (lanes 10 and 11$)$. The first 300 bp of 15-LO DNA has an Apa-1 site consistent with the observed cleavage, whereas 5-LO has only a Pst-1 site (19). Samples were electrophoresed through a $3 \%(\mathrm{wt} / \mathrm{vol})$ agarose gel in TBE buffer containing ethidium bromide $(0.5 \mu \mathrm{g} / \mathrm{ml})$ and photographed under UV illumination. 
$301 \mathrm{~nm}$ (to monitor LX). Detection limits of the LX and LT in this system were determined to be in the picogram range; these values were consistent with those reported by Herrmann et al. (22).

Mono-HETEs were resolved using an RP-HPLC system equipped with a Lambda Max UV detector, model 481, and the column (Beckman Ultrasphere-ODS, $5 \mu \mathrm{m}, 4.6 \mathrm{~mm} \times 25 \mathrm{~cm}$ ) was eluted at $1 \mathrm{ml} /$ min with $\mathrm{MeOH} / \mathrm{H}_{2} \mathrm{O} /$ acetic acid (75:25:0.01, vol/vol/vol). The UV detector was set at $234 \mathrm{~nm}$. Fractions $(1 \mathrm{ml})$ were collected and the presence of radiolabel determined by scintillation spectrophotometry. LT and LX were identified by comparison of individual retention times with those obtained for synthetic standards in each RP-HPLC system. Their quantities were determined by comparing peak areas obtained for calibrated standards in each HPLC system with the corresponding products from individual incubations after correction for the recovery of internal standard. ED peak heights were not used for quantitation in the present experiments but ED reactivities served as an additional criterion to identify amounts of $\mathrm{LX},<5 \mathrm{ng}$, present in some UV tracings.

\section{Results}

Cells obtained and viability. The mean cell number was $11.3 \pm 3.7 \times 10^{6}$ per bronchoscopy (mean \pm SD) with a viability by trypan blue exclusion of $95.6 \pm 3.2 \%(n=10)$, which remained at $92.5 \pm 3.2 \%$ after incubations. Analysis of cell types revealed $96.1 \pm 0.7 \%$ macrophages, $3.0 \pm 0.5 \%$ lymphocytes, $0.6 \pm 0.2 \%$ neutrophils, and $0.3 \pm 0.2 \%$ eosinophils.

15-HETE formation by HAM: regulation by IL-4. Consistent with prior reports ( $1-4)$, HAM exposed to $\left[1-{ }^{14} \mathrm{C}\right] \mathrm{AA}$ generated a product carrying the ${ }^{14} \mathrm{C}$-radiolabel with the retention time of authentic 5-HETE (Fig. 1). In these incubations, HAM also produced material which eluted with the same retention time ( $21 \mathrm{~min}$ ) as 15 -HETE; this product carried radiolabel and coeluted with authentic 15-HETE (Fig. 1).

To determine whether HAM 15-LO activity and 15-HETE generation are regulated by IL-4, as in monocytes (10), cells were incubated in the presence or absence of IL-4. HAM were permeabilized to facilitate substrate availability before addition of $\left[1-{ }^{14} \mathrm{C}\right] \mathrm{AA}\left(20 \mathrm{~min}, 37^{\circ} \mathrm{C}\right)$. Cells exposed to IL-4 generated four to five times more 15-HETE than cells cultured in its absence (Table I). Increases in 15-HETE formation were also obtained with intact cells incubated with IL-4 ( $n=3$; data not shown). In contrast, 5-HETE production by HAM was not influenced in a statistically significant manner by IL- 4 treatment (Table I), suggesting that IL-4 specifically upregulates 15-LO activity.

Identification of HAM 15-LO. 15-HETE can be generated by both 15-LO-dependent and -independent pathways from AA $(23,24)$. Since the cDNA sequence for $15-\mathrm{LO}$ has been determined (19), the presence of this transcript was evaluated in HAM. Given the limited cell numbers ( $10-15 \times 10^{6} \mathrm{HAM} /$ BAL) obtained from nonsmokers, RT-PCR was performed utilizing total cellular RNA (see methods). The RT-PCR product was a 300-bp segment of DNA which corresponded to the first 100 amino acids at the amino terminus of the enzyme. Cycle number and the amount of total cellular RNA were optimized for both $\beta$-actin and 15-LO so that differences in amplified products between samples would be preserved (data not shown). Fig. 2 documents the presence in HAM of an amplified product which corresponds to that expected for $15-\mathrm{LO}$

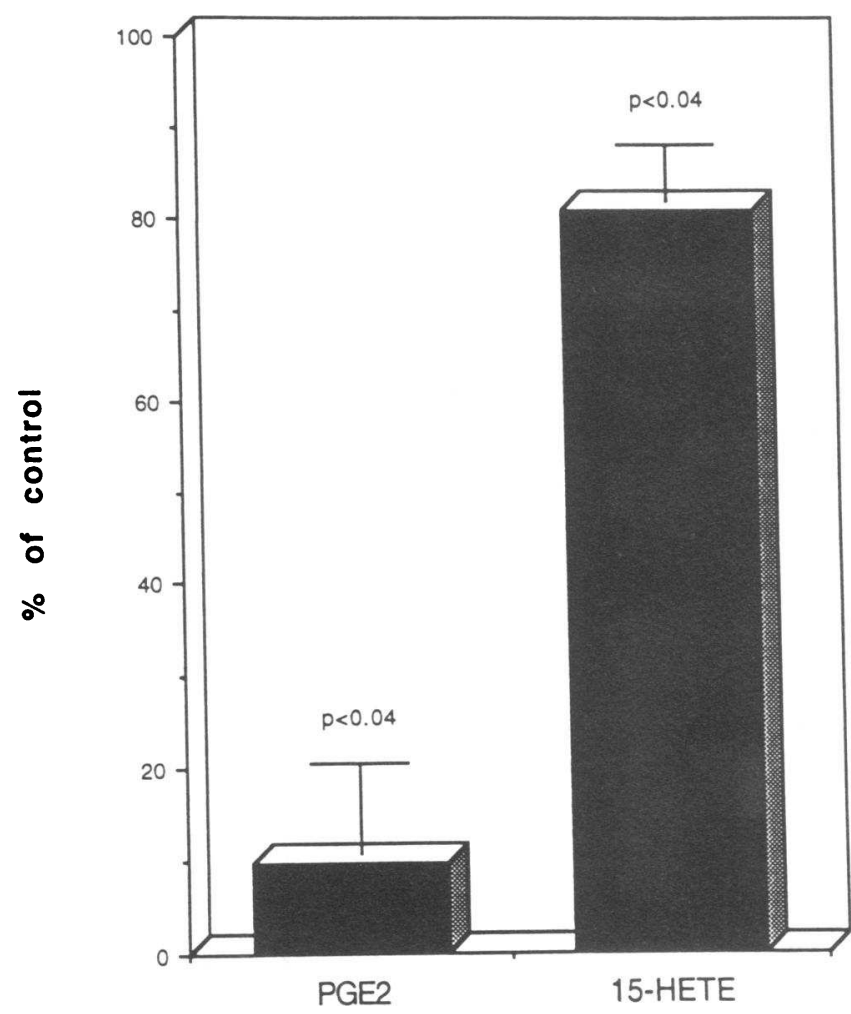

Figure 3. 15-HETE generation by HAM in the presence of cyclooxygenase inhibition. After exposure $\left(72 \mathrm{~h}, 37^{\circ} \mathrm{C}\right)$ to IL-4 $(500 \mathrm{pM})$, HAM $\left(2 \times 10^{6}\right.$ cells $)$ were permeabilized with a rapid freeze/thaw, incubated $\left(15 \mathrm{~min}, 37^{\circ} \mathrm{C}\right)$ in the presence or absence of indomethacin $(100 \mu \mathrm{M})$, and then exposed $\left(20 \mathrm{~min}, 37^{\circ} \mathrm{C}\right)$ to $\left[1-^{14} \mathrm{C}\right] \mathrm{AA}: \mathrm{AA}(20$ $\mu \mathrm{M})$. Products were extracted, injected on RP-HPLC, and eluted with $\mathrm{MeOH} / \mathrm{H}_{2} \mathrm{O} /$ acetic acid (75:25:0.01, vol/vol/vol) (see Methods). Peaks for $\mathrm{PGE}_{2}$ and 15-HETE were identified by comparison with the retention time for authentic standards and quantities were determined by peak area of ${ }^{14} \mathrm{C}$ dpm on radiochromatograms after correction for recovery of the internal standard $\left(\mathrm{PGB}_{2}\right)$. Results are expressed as the percent of control represented by parallel incubations carried out in the absence of indomethacin ( mean \pm SEM, $n=3$ ).

mRNA. Peripheral blood monocyte and human lung tissue RNA were used as known negative (10) and positive sources of 15-LO mRNA (25), respectively. The RT-PCR product was digested by Apa-1 and not by Pst-1 verifying its origin from 15-LO mRNA and not from 5-LO (Fig. 2). In the presence of IL-4, the amount of the amplified product was substantially increased.

Since 15-HETE can also be produced via cyclooxygenasedependent pathways $(23,24,26)$, we examined the generation of 15-HETE by HAM in the presence of cyclooxygenase inhibitors: indomethacin $(100 \mu \mathrm{M})$ and aspirin $(500 \mu \mathrm{M})$. At these concentrations, formation of $\mathrm{PGE}_{2}$ was inhibited while 15HETE production remained $80.7 \%(P<0.04, n=3)$ and $102.5 \%(P=\mathrm{ns}, n=2)$ of control during incubations in the presence of indomethacin and aspirin, respectively (Fig. 3 ). These results indicate that HAM are able to generate 15-HETE utilizing either 15-LO or, to some extent, an indomethacinsensitive cyclooxygenase, although the lipoxygenase pathway appears to be the major route. 

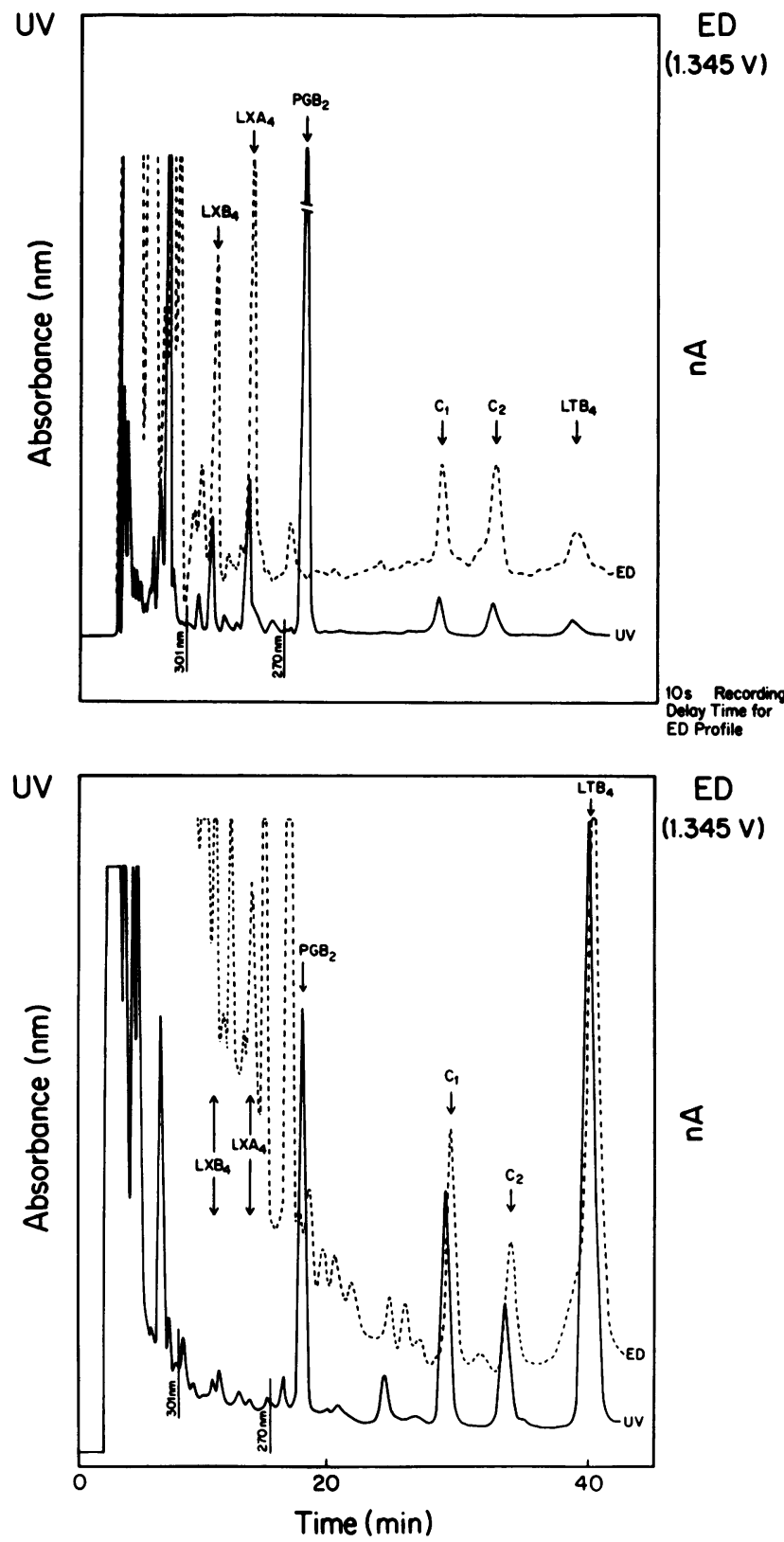

Figure 4. Representative ED-UV RP-HPLC profiles from stimulated HAM. HAM were incubated with $A_{23187}(5 \mu \mathrm{M})$ for $25 \mathrm{~min}$ at $37^{\circ} \mathrm{C}$. Products were extracted and chromatographed with $\mathrm{MeOH} / \mathrm{H}_{2} \mathrm{O}$ (65:35, vol/vol) and trifluoroacetic acid ( $1 \mathrm{mM}$ ) (See Methods). Upper panel: Retention times of the synthetic standards optimized for ED detection of LX. Lower panel: Results in each tracing are representative of incubations with cells from three separate BAL: UV tracing (solid line) and ED detection (dashed tracing). Vertical segments indicate UV monitoring at $301 \mathrm{~nm}$ to detect lipoxins. There was a 10-s recording delay for the tandem ED profile. The ED was optimized for the chemical reactivity of the lipoxins.

LX generation by HAM. With both 5- and 15-LO, HAM possess the ability to produce LX by the sequential lipoxygenation of unesterified AA. Although $\mathrm{LXA}_{4}$ has been identified in BAL fluids of patients with pulmonary diseases (11), the con- tribution of HAM to LX generation has not yet been examined. To this end, HAM were stimulated $\left(25 \mathrm{~min}, 37^{\circ} \mathrm{C}\right)$ with either the calcium ionophore $\left(A_{23187}\right)$ or FMLP and the products obtained were extracted and characterized. HAM activated by ionophore generated predominantly $\mathrm{LTB}_{4}$ and $\mathrm{LTA}_{4}$ (as monitored by appearance of its non-enzymatic hydrolysis products, 6-trans- and 12-epi-6-trans-LTB H $_{4}$ (Fig. 4). These chromatograms also revealed materials with the same retention times and electrochemical reactivity as synthetic $\mathrm{LXA}_{4}$ and $\mathrm{LXB}_{4}$ (Fig. 4). $\mathrm{LXA}_{4}, \mathrm{LXB}_{4}$, and $\mathrm{LTB}_{4}$ were also present to some degree when HAM were incubated alone in the absence of stimuli (Table II). $\mathrm{LXB}_{4}$ levels increased with both $A_{23187^{-}}$and FMLP-triggered stimulation as did $\mathrm{LTB}_{4}$; the amounts of both $\mathrm{LXA}_{4}$ and $\mathrm{LXB}_{4}$ were clearly less than those of agonist-induced $\mathrm{LTB}_{4}$ formation. In contrast, $\mathrm{LXA}_{4}$ levels were evident before addition of HAM agonists and did not increase after activation. The ratios of LT to LX production were $0.6,2.3$, and 21.0 with no stimulus, FMLP, or $A_{23187}$, respectively.

A role for $\mathrm{LTA}_{4}$ in $\mathrm{LX}$ generation by $\mathrm{HAM}$. Since 15-LO can convert $\mathrm{LTA}_{4}$ to $\operatorname{LX}(7,27)$, we examined whether the low levels of LX produced by HAM from endogenous sources could be increased by exposure to $\mathrm{LTA}_{4}$. In the presence of LTA $_{4}$, HAM generated $\sim 2$ times more LXA $_{4}$ and 10 times more $\mathrm{LXB}_{4}$ ( Table III). In these experiments, $\mathrm{LTB}_{4}$ formation also increased 7-fold after $\mathrm{LTA}_{4}$ exposure. Incubation with IL$4(72 \mathrm{~h})$ did not further enhance HAM production of LX from LTA $_{4}$ with either intact or permeabilized HAM using these conditions. Also, IL-4-primed HAM stimulated with $A_{23187}$ ( 5 $\mu \mathrm{M}, 20 \mathrm{~min}, 37^{\circ} \mathrm{C}$ ) did not generate statistically significant increases in LX levels from endogenous source of substrate above those reported in Table II (data not shown).

\section{Discussion}

The present results indicate that HAM possess $15-\mathrm{LO}$ activity and can generate 15-HETE. 15-HETE was identified by several criteria: retention time on RP-HPLC, radiolabeling, and coelution with authentic 15-HETE (Fig. 1). 15-LO mRNA was also demonstrated by RT-PCR and selective digestion with a restriction endonuclease of the amplified product (Fig. 2). Exposure of HAM to IL-4 selectively increased 15-HETE formation (Table I) and 15-LO mRNA levels (Fig. 2). In addition, HAM production of 15 -HETE was reduced by only $20 \%$ in the presence of indomethacin, but was not affected by aspirin (Fig. 3). These cells were also able to generate $\mathrm{LXB}_{4}$ from endogenous stores in the presence of stimuli (Fig. 4, Table II) and both $\mathrm{LXA}_{4}$ and $\mathrm{LXB}_{4}$ when incubated in the presence of exogenous $\mathrm{LTA}_{4}$ (Table III). Together these observations are the first to identify $15-\mathrm{LO}$ activity in HAM and demonstrate a potential role for these cells in contributing to the formation of the 15HETE and LX found in BAL fluid $(5,11)$.

Several cell types of the respiratory tract can produce 15HETE including human tracheal epithelial cells, eosinophils, and polymorphonuclear leukocytes (reviewed in reference 23 ). In the present study, the cell population from freshly obtained BAL fluids represented $>96 \%$ HAM, and thus, the 15HETE identified by physical methods (Fig. 1) does not appear 


\begin{tabular}{|c|c|c|c|c|c|}
\hline & $\mathrm{LXA}_{4}$ & $\mathrm{LXB}_{4}$ & $\mathrm{LTB}_{4}$ & $\begin{array}{c}{ }_{16-t r a n s-\mathrm{LTB}_{4}} \\
+ \text { 12-epi-6-trans-LTB }\end{array}$ & $\Sigma L T / \Sigma L X$ \\
\hline \multicolumn{6}{|c|}{ ng/10 $10^{6}$ cells } \\
\hline HAM & $1.30 \pm 0.22$ & $0.17 \pm 0.04$ & $0.30 \pm 0.24$ & $0.29 \pm 0.18$ & 0.63 \\
\hline HAM + fMLP $\left(10^{-7} M\right)$ & $0.60 \pm 0.13$ & $0.23 \pm 0.13$ & $1.77 \pm 0.91$ & $0.88 \pm 0.57$ & 2.26 \\
\hline $\mathrm{HAM}+A_{23187}(5 \mu \mathrm{M})$ & $0.70 \pm 0.08$ & $0.51 \pm 0.15^{*}$ & $30.22 \pm 6.47^{*}$ & $10.77 \pm 1.84^{*}$ & 20.95 \\
\hline
\end{tabular}

HAM $\left(1.85-3.35 \times 10^{6}\right.$ cells $\left./ \mathrm{ml}\right)$ isolated from BAL fluid were incubated $\left(25 \mathrm{~min}, 37^{\circ} \mathrm{C}\right)$ with either $A_{23187}(5 \mu \mathrm{M})$, FMLP $(0.1 \mu \mathrm{M})$, or vehicle alone. Materials were extracted and chromatographed as described under Methods. Results represent the mean \pm SEM of three separate experiments. Values for $\mathrm{LXA}_{4}$ and $\mathrm{LXB}_{4}$ are corrected for isolation-induced isomerization (see reference 15). 6-trans-LTB $\mathrm{L}_{4}$ and 12-epi-6-trans-LTB were produced in approximately equal amounts in each chromatogram. $\mathrm{PGB}_{2}$ recovery was $89.2 \pm 8.5 \%$. ${ }^{*} P<0.10$.

to be the result of contaminating cells. The presence of 15-LO activity and its induction in HAM may be relevant in humans, since 15-LO-derived products display actions in experimental models involving the respiratory tract (4). 15-HETE inhibits vascular cyclooxygenase (23), diverts LT production, and regulates signal transduction after esterification into membrane phospholipids from where it can be released upon subsequent cell activation and serve to "prime" the cell membrane (28). 15-HETE is a major eicosanoid in lung tissues $(5,6)$ and levels of both 15-HETE, identified by gas chromatography/mass spectrometry, and 15-LO mRNA, identified by RT-PCR, increase in BAL fluid from asthmatics after antigen challenge ( 5 , 25, 29). Since HAM are the predominant cell type in BAL fluid and possess 15-LO mRNA, they are a likely source of 15-LO transcription. Thus, HAM have the potential to contribute to 15-HETE production in lung tissues.

In addition to 15-LO, 15-HETE can be generated by cyclooxygenase-dependent pathways in endothelial (23) and epithelial cells (24). Recently, isozymes of PGH synthase were identified whose ability to generate 15 -HETE is enhanced by aspirin and inhibited by indomethacin $(24,26)$. The data shown in Fig. 3 demonstrates that, in concentrations which blocked $\mathrm{PGE}_{2}$ formation by HAM, indomethacin suppressed 15-HETE production by $19.3 \%(P<0.04)$ while aspirin had no apparent impact. These results suggest that the generation of 15-HETE by HAM occurs primarily via the 15-LO pathway;

Table III. LTA -induced Increase in LX and LT Formation

\begin{tabular}{|c|c|c|c|c|}
\hline & $\mathrm{LXA}_{4}$ & $\mathrm{LXB}_{4}$ & $\mathrm{LTB}_{4}$ & $\Sigma L T / \Sigma L X$ \\
\hline \multicolumn{5}{|c|}{$n g / 10^{6}$ cells } \\
\hline HAM alone & $1.34 \pm 0.39$ & $0.43 \pm 0.06$ & $0.95 \pm 0.43$ & 0.93 \\
\hline $\mathrm{HAM}+\mathrm{LTA}_{4}$ & $3.05 \pm 0.51$ & $4.12 \pm 1.79^{*}$ & $6.56 \pm 0.96^{\ddagger}$ & 0.69 \\
\hline
\end{tabular}

${ }^{*} P<0.10$. ${ }^{\ddagger} P<0.02$. HAM $\left(1.0-1.5 \times 10^{6}\right.$ cells $\left./ \mathrm{ml}\right)$ were incubated $\left(25 \mathrm{~min}, 37^{\circ} \mathrm{C}\right)$ either alone or in the presence of $\mathrm{LTA}_{4}(15$ $\mu \mathrm{M})$. Results represent the mean \pm SEM from three separate bronchoalveolar lavages. Values for $\mathrm{LXA}_{4}$ and $\mathrm{LXB}_{4}$ are corrected for isolation-induced isomerization (see reference 15 ). $\mathrm{PGB}_{2}$ recovery was $75.4 \pm 4.8 \%$. however, these cells can also convert AA into 15-HETE by an indomethacin-sensitive PGH synthase.

We found that the 15-LO activity present in HAM is upregulated after IL-4 treatment (Table I); our observation extends the previous demonstration of 15 -LO induction by IL-4 in peripheral blood monocytes (10), known precursors of HAM. High levels of IL-4 are present in asthmatic lungs secondary to elaboration by the $T_{H 2}$ subset of T-helper lymphocytes and mast cells (8). It follows that 15-HETE generation by HAM exposed to IL-4 may represent a critical aspect of cell-cell interactions during immune responses in the lung.

It has been previously shown that $\mathrm{LXA}_{4}$ is detected in $\mathrm{BAL}$ fluids from patients with respiratory diseases (11); the cell types involved in LX formation in the lung are not known. Formation of LX by activated HAM (Fig. 4, Table II) suggests interactions between 5-LO and 15-LO. For example, 5-LO could provide $\mathrm{LTA}_{4}$ for conversion to LX by HAM 15-LO. This route proceeds via a 5(6)-epoxytetraene intermediate, the equivalent of 15-hydroxy-LTA , $_{4}$ and has been documented with soybean 15-LO (27), bronchial tissue, and nasal polyps (30). In support of this biosynthetic origin, LX formation is increased when HAM are incubated in the presence of $\mathrm{LTA}_{4}$ ( Table III). Utilization of extracellular $\mathrm{LTA}_{4}$ by HAM may be an important biosynthetic route for $\mathrm{LX}$, as multiple cell types found in the lung such as mast cells (31), cytokine-primed neutrophils (16), and macrophages themselves (as monitored in the present study by detection of LTA $_{4}$-derived nonenzymatic hydrolysis products; Table II) are capable of releasing $\mathrm{LTA}_{4}$ into the extracellular milieu. In addition, 15-LO can also provide 15-HETE to 5-LO for further conversion to LX. Recently, HAM were reported to generate prodigious amounts of LX (32) via the transcellular metabolism of exogenous 15HETE similar to previous observations with human neutrophils (7). In this regard, airway epithelial cells display high levels of $15-\mathrm{LO}$ activity $(7,21)$. Since $\mathrm{LXA}_{4}$ was detected in HAM prior to the addition of agonists, it is possible that the mechanical agitation of bronchoscopy may have triggered $\mathrm{LXA}_{4}$ and to some extent $\mathrm{LXB}_{4}$ formation present in the in vitro incubations ( Table II). Thus HAM could participate in the generation of lipoxins via at least two routes: (1) sequential 15-LO (donated 15-HETE) followed by 5-LO of HAM, or (2) by transformation of exogenous $\mathrm{LTA}_{4}$ by $15-\mathrm{LO}$ of HAM. Although $\mathrm{LXA}_{4}$ levels were not increased by typical HAM ago- 
nists (FMLP and $A_{23187}$ ), $\mathrm{LXB}_{4}$ formation was clearly increased (Table II). Together with the finding that LTA $_{4}$ increases $\mathrm{LXB}_{4}$ formation (10 times), it appears that HAM possess a $\mathrm{LXB}_{4}$ synthetase (Table III). Macrophages from other species, such as the rainbow trout, generate microgram amounts of LX from endogenous sources of substrate (33), indicating that the lipoxin structure has a long evolutionary history and suggesting that its formation in humans may mark a basic functional role of these eicosanoids.

Because there are large numbers of HAM in alveoli and LX possess modulatory actions in experimental models at concentrations in the range of those reported in Table III, the participation of HAM in the formation of LX in the lung may be relevant in humans. For example, $\mathrm{LXA}_{4}$ antagonizes $\mathrm{LTC}_{4}$-induced contraction of human bronchi (13) and bronchoconstriction of asthmatic human airways (14). $\mathrm{LXA}_{4}$ also inhibits $\mathrm{LTB}_{4}$-induced inflammation (34) and down-regulates $\mathrm{LTB}_{4}$ receptors on lymphocytes (35). The role of $\mathrm{LXB}_{4}$ in the lung remains to be fully appreciated; however, $\mathrm{LXB}_{4}$ has been demonstrated in submicromolar amounts to inhibit both $\mathrm{LTB}_{\mathbf{4}^{-}}$ and FMLP-stimulated neutrophil chemotaxis (36), stimulate myelopoiesis (37), and exert a radioprotective effect in vitro (38).

In conclusion, HAM possess $15-\mathrm{LO}$ activity and can participate in the biosynthesis of both 15-HETE and LX in the respiratory tract. Furthermore, the production of these compounds by HAM can be enhanced by cytokines, such as IL-4, and exogenous substrates, such as LTA $_{4}$. Cell-cell interactions in the lung may represent important regulatory mechanisms for bioactive eicosanoid formation and action during pulmonary inflammation.

\section{Acknowledgments}

We thank Sharon Lynch and Laura Sailor for technical assistance, Dr. Stefano Fiore for helpful discussions regarding ED-UV RP-HPLC, Guo-Ping Shi for his expertise and assistance with RT-PCR, Susan Turci (Hematology Division, Brigham and Women's Hospital) for synthesis of the oligonucleotides for 15-LO, the Brigham and Women's Hospital Lung Transplantation Tissue Bank for donation of the lung RNA, and Mary Halm Small for skillful preparation of the manuscript.

This work was supported in part by National Institutes of Health grants GM-38765 (to Dr. Serhan), HL-44712 (to Dr. Chapman), and HL-33009 (to Dr. Drazen). Dr. Serhan is a recipient of an Established Investigator Award from the American Heart Association. Dr. Romano is on leave from the Department of Medical Pathology and Mediterranean Medicine, University of Messina, Italy.

\section{References}

1. Fels, A. O., and Z. A. Cohn. 1986. The alveolar macrophage. J. Appl. Physiol. 60:353-369.

2. Fels, A. O., N. A. Pawloski, E. B. Cramer, T. K. C. King, Z. A. Cohn, and W. A. Scott. 1982. Human alveolar macrophages produce leukotriene $B_{4}$. Proc. Natl. Acad. Sci. USA. 79:7866-7870.

3. Laviolette, M., R. Coulombe, S. Picard, P. Braquet, and P. Borgeat. 1986 Decreased leukotriene $B_{4}$ synthesis in smokers' alveolar macrophages in vitro. $J$. Clin. Invest. 77:54-60.

4. Dahlén, S.-E., and C. N. Serhan. 1991. Lipoxins: Bioactive lipoxygenase interaction products. In Lipoxygenases and Their Products. S. P. Crooke and A. Wong, editors. Academic Press, Inc., San Diego. 235-276.

5. Kumlin, M., M. Hamburg, E. Granström, T. Björck, B. Dahlén, H. Matsuda, O. Zetterström, and S.-E. Dahlén. 1990. 15(S)-Hydroxyeicosatetraenoic acid is the major arachidonic acid metabolite in human bronchi: Association with airway epithelium. Arch. Biochem. Biophys. 282:254-262.

6. Hamberg, M., P. Hedqvist, and K. Rådengran. 1980. Identification of 15-hydroxy-5,8,11,13-eicosatetraenoic acid (15-HETE) as a major metabolite of arachidonic acid in human lung. Acta Physiol. Scand. 110:219-221.

7. Serhan, C. N. 1991. Lipoxins: Eicosanoids carrying intra- and intercellular messages. J. Bioenerget. Biomembr. 23:105-122.

8. Robinson, D. S., Q. Hamid, S. Ying, A. Tsicopoulos, J. Barkans, A. M. Bentley, C. Corrigan, S. Durham, and A. B. Kay. 1992. Predominant $\mathrm{T}_{\mathrm{H}}$-like bronchoalveolar T-lymphocyte population in atopic asthma. N. Engl. J. Med. 326:298-304.

9. Park, L. S., D. Friend, H. M. Sassenfeld, and D. L. Urdal. 1987. Characterization of the human B cell stimulatory factor 1 receptor. J. Exp. Med. 166:476488.

10. Conrad, D. J., H. Kuhn, M. Mulkins, E. Highland, and E. Sigal. 1992. Specific inflammatory cytokines regulate the expression of human monocyte 15-lipoxygenase. Proc. Natl. Acad. Sci. USA. 89:217-221.

11. Lee, T. H., A. E. G. Crea, V. Gant, B. W. Spur, B. E. Marron, K. C. Nicolaou, E. Reardon, M. Brezinski, and C. N. Serhan. 1990. Identification of lipoxin $A_{4}$ and its relationship to the sulfidopeptide leukotrienes $C_{4}, D_{4}$ and $E_{4}$ in the bronchoalveolar lavage fluids obtained from patients with selected pulmonary diseases. Am. Rev. Respir. Dis. 141:1453-1458.

12. Dahlen, S.-E., M. Kumlin, T. Bjorck, J. Raud, E. Wikstrom, and P. Hedqvist. 1991. Lipoxins and other lipoxygenase products with relevance to inflammatory reactions in the lung. Ann. NY Acad. Sci. 629:262-273.

13. Björck, T., K. C. Nicolaou, and S.-E. Dahlén. 1989. Lipoxin $A_{4}$ interacts with leukotriene $\mathrm{C}_{4}$ in human bronchi. Am. Rev. Respir. Dis. 139:A78. (Abstr.)

14. Christie, P. E., B. W. Spur, and T. H. Lee. 1992. The effects of lipoxin A on airway responses in asthmatic subjects. Am. Rev. Respir. Dis. 125:1281-1284.

15. Romano, M., and C. N. Serhan. 1992. Lipoxin generation by permeabilized human platelets. Biochemistry. 31:8269-8277.

16. Fiore, S., and C. N. Serhan. 1990. Formation of lipoxins and leukotrienes during receptor-mediated interactions of human platelets and recombinant human granulocyte/macrophage colony-stimulating factor-primed neutrophils. $J$. Exp. Med. 172:1451-1457.

17. Chirgwin, J. M., A. E. Przybyla, R. J. MacDonald, and W. J. Rutter. 1979. Isolation of biologically active ribonucleic acid from sources enriched in ribonuclease. Biochemistry. 18:5294-5299.

18. Munger, J. S., G.-P. Shi, E. A. Mark, D. T. Chin, C. Gerard, and H. A. Chapman. 1991. A serine esterase released by human alveolar macrophages is closely related to liver microsomal carboxylesterases. J. Biol. Chem. 266:1883218838.

19. Sigal, E., C. S. Craik, E. Highland, D. Grunberger, L. L. Costello, R. A. F. Dixon, and J. Nadel. 1988. Molecular cloning and primary structure of human 15-lipoxygenase. Biochem. Biophys. Res. Commun. 157:457-464.

20. Ponte, P., S. Y. Ng, J. Engel, P. Gunning, and L. Kedes. 1984. Evolutionary conservation in the untranslated regions of actin mRNAs: DNA sequence of a human beta-actin cDNA. Nucleic Acids Res. 12:1687-1696.

21. Yamamoto, S. 1992. Mammalian lipoxygenase: molecular structures and functions. Biochim. Biophys. Acta. 1128:117-131.

22. Herrmann, T., D. Steinhilber, J. Knospe, and H. J. Roth. 1988. Determination of picogram amounts of lipoxin $\mathrm{A}_{4}$ and lipoxin $\mathrm{B}_{4}$ by high-performance liquid chromatography with electrochemical detection. J. Chromatogr. 428:237245.

23. Spector, A. A., J. A. Gordon, and S. A. Moore. 1988. Hydroxyeicosatetraenoic acids (HETEs). Prog. Lipid Res. 27:271-323.

24. Holtzman, M. J., J. Turk, and L. P. Shornick. 1992. Identification of a pharmacologically distinct prostaglandin synthase in cultured epithelial cells. $J$. Biol. Chem. 267:21438-21445.

25. Funk, C. D., and G. A. FitzGerald. 1991. Eicosanoid forming enzyme mRNA in human tissues. J. Biol. Chem. 266:12508-12513.

26. Meade, E. A., W. L. Smith, and D. L. DeWitt. 1993. Differential inhibition of prostaglandin endoperoxide synthase (cyclooxygenase) isozymes by aspirin and other non-steroidal anti-inflammatory drugs. J. Biol. Chem. 268:6610-6614.

27. Serhan, C. N., K. A. Sheppard, and S. Fiore. 1990. Lipoxin formation: evaluation of the role and actions of leukotriene $\mathrm{A}_{4}$. Adv. Prostaglandin Thromboxane Res. 20:54-62.

28. Brezinski, M. E., and C. N. Serhan. 1990. Selective incorporation of (15S)-hydroxyeicosatetraenoic acid in phosphatidylinositol of human neutrophils: agonist-induced deacylation and transformation of stored hydroxyeicosanoids. Proc. Natl. Acad. Sci. USA. 87:6248-6252. 
29. Murray, J. J., A. B. Tonnel, A. R. Brash, L. J. Roberts, II, P. Gosset, R. Workman, A. Capron, and J. S. Oates. 1986. Release of prostaglandin $\mathrm{D}_{2}$ into human airways during acute antigen challenge. $N$. Engl. J. Med. 315:800-804.

30. Edenius, C., M. Kumlin, T. Björck, A. Änggård, and J. Å. Lindgren. 1990 Lipoxin formation in human nasal polyps and bronchial tissue. FEBS (Fed. Eur. Biochem. Soc.) Lett. 272:25-28.

31. Dahinden, C. A., R. M. Clancy, M. Gross, J. M. Chiller, and T. E. Hugli. 1985. Leukotriene $C_{4}$ production by murine mast cells: evidence of a role for extracellular leukotriene $\mathrm{A}_{4}$. Proc. Natl. Acad. Sci. USA. 82:6632-6636.

32. Chavis, C., P. Godard, A. Crastes de Paulet, and M. Damon. 1992. Formation of lipoxins and leukotrienes by human alveolar macrophages incubated with 15(S)-HETE: a model for cellular cooperation between macrophages and airway epithelial cells. Eicosanoids. 5:203-211.

33. Pettitt, T. R., A. F. Rowley, S. E. Barrow, A. I. Mallet, and C. J. Secombes. 1991. Synthesis of lipoxins and other lipoxygenase products by macrophages from the rainbow trout, Oncorhynchus mykiss. J. Biol. Chem. 266:8720-8726.
34. Hedqvist, P., J. Raud, U. Palmertz, J. Haeggström, K. C. Nicolaou, and S.-E. Dahlén. 1989. Lipoxin $A_{4}$ inhibits leukotriene $B_{4}$-induced inflammation in the hamster cheek pouch. Acta Physiol. Scand. 137:571-572.

35. Wong, P.Y.-K., and K. T. Lin. 1992. Lipoxin $A_{4}$ modulates guinea pig T-lymphocytes function by down regulation of leukotriene $B_{4}$ receptors. 8th International Conference on Prostaglandins and Related Compounds, Montreal, Canada. Abstr. 256.

36. Lee, T. H., C. E. Horton, U. Kyan-Aung, D. Haskard, A. E. Crea, and B. W. Spur. 1989. Lipoxin $A_{4}$ and lipoxin $B_{4}$ inhibit chemotactic responses of human neutrophils stimulated by leukotriene $\mathrm{B}_{4}$ and $N$-formyl-L-methionyl-Lleucyl-L-phenylalanine. Clin. Sci. 77:195-203.

37. Stenke, L., M. Mansour, C. Edenius, P. Reizenstein, and J. A. Lindgren. 1991. Formation and proliferative effects of lipoxins in human bone marrow. Biochem. Biophys. Res. Commun. 180:255-261.

38. Walden, T. L. 1988. Radioprotection of mouse hematopoietic stem cells by leukotriene $\mathrm{A}_{4}$ and lipoxin $\mathrm{B}_{4}$. J. Radiat. Res. 29:255-260. 